\title{
A demethylating agent enhances chemosensitivity to vinblastine in a xenograft model of renal cell carcinoma
}

\author{
HIROKI IWATA $^{1}$, HIROMI SATO ${ }^{1}$, RINA SUZUKI ${ }^{1}$, RYOTA YAMADA ${ }^{1}$, SAKI ICHINOMIYA ${ }^{1}$, \\ MIDORI YANAGIHARA ${ }^{1}$, HIROYUKI OKABE ${ }^{2}$, YUKO SEKINE ${ }^{2}$, TOMOHIRO YANO $^{3}$ and KOICHI UENO ${ }^{1}$ \\ Departments of ${ }^{1}$ Geriatric Pharmacology and Therapeutics, and ${ }^{2}$ Practical Pharmacology, \\ Graduate School of Pharmaceutical Sciences, Chiba University, 1-8-1 Inohana, Chuo-ku, Chiba 260-8675; \\ ${ }^{3}$ Laboratory of Molecular Patho-physiology, Faculty of Life Sciences, Toyo University, \\ 1-1-1 Izumino, Itakura, Oura, Gunma 374-0193, Japan
}

Received December 30, 2010; Accepted February 25, 2011

DOI: $10.3892 /$ ijo.2011.999

\begin{abstract}
Renal cell carcinoma (RCC) is resistant to chemotherapy partly due to the overexpression of the P-glycoprotein. Several tumor suppressor genes have been reported to be silenced by hypermethylation of the promoter region in RCC. We recently reported that the in vitro cytotoxicity of vinblastine (VBL) was enhanced by pre-treatment with the demethylating agent, 5-aza-2'-deoxycytidine (Aza), in the RCC cell line, Caki-1. In this study, we investigated the combined effect of Aza and VBL in a Caki-1 xenograft model and in other RCC cell lines in vitro. In the xenograft model, tumor volume and weight were significantly suppressed in the co-treatment group, compared to the control, and the expressions of P-glycoprotein, Bcl-2 and cyclin B1 were reduced. Thus, this combined effect could be mediated by the accumulation of intracellular VBL and the enhancement of apoptosis and cell cycle arrest. Moreover, the cytotoxicity of VBL was enhanced in vitro in three RCC cell lines by Aza treatment. These findings suggest that the combination treatment with Aza and VBL is effective against RCC.
\end{abstract}

\section{Introduction}

Kidney cancer accounts for approximately $2 \%$ of all cancers (1), the most common form of kidney cancer in adults being renal cell carcinoma (RCC). Approximately $33 \%$ of patients have metastatic disease at presentation, and $40 \%$ of patients undergoing nephrectomy eventually develop metastasis (2). In addition, advanced RCC has been reported to be highly resistant to conventional chemotherapy (3). Thus, the prognosis of

Correspondence to: Dr Hiroki Iwata, Department of Geriatric Pharmacology and Therapeutics, Graduate School of Pharmaceutical Sciences, Chiba University, 1-8-1 Inohana, Chuo-ku, Chiba 260-8675, Japan

E-mail: hirokiiwata@graduate.chiba-u.jp

Key words: renal cancer, 5-aza-2'-deoxycytidine, combined effect metastatic RCC is extremely poor, with 5-year survival rates of $5-10 \%$ (4). Previously, immunotherapy with interferon- $\alpha$ and interleukin-2 was the general therapy against metastatic RCC, but the response rate was only $10-20 \%$ (4). Recently, several molecular-targeted agents, such as sorafenib (5), sunitinib (6), everolimus (7) and temsirolimus (8) have been approved for RCC treatment. Thus, a wide range of choices is now available for RCC treatment (9). However, it has been reported that these molecular-targeted agents often cause severe adverse effects (10). Therefore, these agents should be administered carefully. Furthermore, new therapeutic strategies for the treatment of metastatic RCC need to be established.

The multidrug resistance 1 gene $(M D R l)$ product $\mathrm{P}$-glycoprotein $(\mathrm{P}-\mathrm{gp})$ functions as an energy-dependent transport pump capable of decreasing the intracellular concentration of a wide range of anticancer agents, thereby conferring chemoresistance to cancer cells. Agents that inhibit P-gp function, such as cyclosporine A and valspodar (PSC-833), have been tested in clinical trials. However, these agents show toxic sideeffects and pharmacokinetic interactions. New P-gp inhibitors with fewer pharmacokinetic interactions need to be developed $(11,12)$. Evidence suggests that P-gp could contribute to the chemoresistance of RCC. For instance, the overexpression of $\mathrm{P}$-gp is found in $76 \%$ of RCC specimens (13), and P-gp activity is higher in RCC cells than in normal renal cells (14). Thus, $\mathrm{P}-\mathrm{gp}$ could be an attractive target for overcoming chemoresistance.

It has been shown that some tumor-suppressor genes are silenced by hypermethylation of the promoter region in various cancers, and this could contribute to carcinogenesis and cancer progression (15). Several tumor suppressor genes have been reported to be inactivated by promoter hypermethylation in RCC. Examples include genes encoding von Hippel-Lindau (VHL) (2), E-cadherin $(16,17)$ and RASSF1A (18). DNAdemethylating agents can reverse hypermethylation by inhibiting DNA methyltransferase, restoring gene expression, and exerting antitumor effects, at least in laboratory models $(19,20)$. In the clinical setting, 5-aza-2'-deoxycytidine (Aza) (21) and 5 -azacytidine (22) are administered to patients with myelodysplastic syndrome. Unfortunately, these demethylating agents have shown little activity in solid tumors (23). 
Current cancer treatment approaches involve, in most cases, the combination of two or more anticancer drugs. This occurs for the reason that the administration of a single agent is not expected to be highly effective. Moreover, tumors often acquire resistance to the administered drug. Although the administration of a demethylating agent alone is clinically ineffective against solid tumors, the combined treatment with demethylating agents and cytotoxic drugs has shown potential antitumor activity in vitro and in vivo (24-26). It has been hypothesized that demethylating agents restore the expression of epigenetically silenced genes and sensitize cancer cells to anticancer drugs (25). However, reports on the combined effect of demethylating agents and cytotoxic drugs against RCC are limited.

We recently reported that the in vitro cytotoxicity of vinblastine (VBL) is enhanced by the pre-treatment of the RCC cell line, Caki-1, with Aza (27). VBL is one of the few classical cytotoxic drugs against RCC (28). We also showed that the combined effect of Aza and VBL was induced via the restoration of the connexin $(\mathrm{Cx}) 32$ gene by demethylation of the promoter region and depression of P-gp expression (27). The gene encoding the gap junction protein, $\mathrm{Cx} 32$, is considered to be a tumor-suppressor gene in RCC (29). In this study, we investigated the combined effect of Aza and VBL in a Caki-1 xenograft model and in other RCC cell lines in vitro. We discuss the usefulness of Aza for the treatment of RCC.

\section{Materials and methods}

Materials. Aza was purchased from Sigma (St. Louis, MO, USA) and VBL was obtained from Wako Pure Chemicals (Osaka, Japan). Aza and VBL were dissolved in dimethyl sulfoxide (DMSO) at a concentration of $100 \mathrm{mM}$ and $1 \mathrm{mM}$, respectively, and diluted in culture medium for in vitro studies. Alternatively, Aza and VBL were dissolved in phosphatebuffered saline (PBS) for in vivo studies. 3-[4, 5-dimethyl thiazol-2-yl]-2, 5-diphenyltetrazolium bromide (MTT; Wako Pure Chemicals) was dissolved in PBS at a concentration of $5 \mathrm{mg} / \mathrm{ml}$ and diluted to $0.25 \mathrm{mg} / \mathrm{ml}$ in serum-free medium. PCR primers were purchased from Sigma Genosys (Hokkaido, Japan).

Cell culture. Three human RCC cell lines, Caki-1 (ATCC, Manassas, VA, USA), 786-O and A498 (gifts from Dr Tomohiro Yano, Toyo University, Japan), were used. Caki-1 cells were maintained in McCoy's 5A medium (Gibco, Gaithersburg, MD, USA) containing $10 \%$ fetal bovine serum (FBS), 100 units $/ \mathrm{ml}$ of penicillin, and $100 \mu \mathrm{g} / \mathrm{ml}$ of streptomycin (Gibco). 786-O and A498 cells were maintained in Dulbecco's modified Eagle's medium (Sigma) supplemented with 10\% FBS and antibiotics as described above. All cells were incubated at $37^{\circ} \mathrm{C}$ in $5 \% \mathrm{CO}_{2}$.

Mouse xenograft experiments. Approximately $1 \times 10^{7}$ Caki-1 cells in Matrigel (BD Biosciences, Bedford, MA, USA) were transplanted subcutaneously into the right flank region of 5-week-old male athymic BALB/c nu/nu mice (Charles River Laboratories Japan Inc., Yokohama, Japan). On day 9, mice were randomized into four groups (six mice per group) as follows: Untreated control, Aza alone, VBL alone, or a combi- nation of Aza and VBL. On days 9, 16, 23 and 30, Aza $(1.5 \mathrm{mg} / \mathrm{kg}$ ) was administered by intraperitoneal (i.p.) injection and on days 12, 19, 26 and 33, VBL $(1.5 \mathrm{mg} / \mathrm{kg})$ was also administered by i.p. injection. The dose of each drug was set on the basis of the results of preliminary experiments (data not shown). Untreated control mice and mice receiving a single agent received injections of PBS on the days of therapy. Body weight and tumor diameter were measured every 2 or 3 days. Tumor volume was calculated as [ $\pi / 6 \times$ large diameter $\mathrm{x}$ (small diameter) $\left.{ }^{2}\right]$ and relative tumor volume was determined as (tumor volume on day 34)/(tumor volume on day 9). On day 34 , tumors were carefully removed, weighed, and stored at $-80^{\circ} \mathrm{C}$ until RNA or protein extraction. All animal experiments were carried out according to the Chiba University Institutional Animal Care and Use Committee.

Drug treatment. Cells were plated on day -1 and treated according to four protocols as follows: Untreated control, Aza alone, VBL alone, or Aza followed by VBL. On day 0, the culture medium was removed and new medium containing Aza (or vehicle) was added. On day 3, the medium was replaced with a new medium containing VBL (or vehicle). The assays were performed on day 5 .

Cell viability assay. Cells were plated in 96-well microtiter plates and treated as described above. Thereafter, the medium was removed and $100 \mu 1$ of MTT solution were added. After 1-h incubation, the MTT solution was replaced with $100 \mu \mathrm{l}$ of DMSO to dissolve the tetrazolium crystals. Finally, the absorptions were read at a test wavelength of $540 \mathrm{~nm}$ and a reference wavelength of $650 \mathrm{~nm}$ with a Multiskan JX microplate reader (Thermo Labsystems, Cheshire, UK). Cell viability (\%) was calculated as [optical density (OD) of the treated wells $] /(\mathrm{OD}$ of the control wells) x 100 .

Flow cytometric analysis of the cell cycle. Cells were plated in $60-\mathrm{mm}$ dishes and treated as described above. Thereafter, the cells were collected and fixed with $80 \%$ ethanol. Before analysis, the cells were incubated at $37^{\circ} \mathrm{C}$ for $30 \mathrm{~min}$ in PBS containing $0.05 \mathrm{mg} / \mathrm{ml}$ of propidium iodide (Wako Pure Chemicals) and $0.2 \mathrm{mg} / \mathrm{ml}$ of RNase A (Sigma). The cell suspension was passed through a nylon mesh and analyzed on a MoFlo cell sorter (Dako Cytomation, Kyoto, Japan).

Reverse transcription real-time PCR analysis. Cells were seeded in 6-well microtiter plates and treated as described above. Total RNA was extracted from the treated cells and xenografts with the RNeasy mini kit (Qiagen, Valencia, CA, USA) according to the manufacturer's instructions. cDNA was synthesized in a $40-\mu \mathrm{l}$ reaction mixture with $1 \mu \mathrm{g}$ of total RNA by using the PrimeScript RT Reagent Kit (Takara Bio Inc., Shiga, Japan). Real-time PCR was performed with the ABI StepOne Real-Time PCR System (Applied Biosystems Japan Ltd., Tokyo, Japan) and SYBR Premix Ex Taq (Takara Bio Inc.). Primer sequences (except those for $C x 32$ ) are listed in Table I. For amplification of the $C \times 32$ gene, we used the Hs_GJB1_1_SG QuantiTect Primer Assay (200) (Qiagen). The PCR reaction was performed at $95^{\circ} \mathrm{C}$ for $10 \mathrm{sec}$, followed by 40 cycles at $95^{\circ} \mathrm{C}$ for $5 \mathrm{sec}$ and $60^{\circ} \mathrm{C}$ for $31 \mathrm{sec}$. All data were normalized to the internal standard RPL32. 
Table I. Primer sequences for real-time PCR.

\begin{tabular}{|c|c|c|c|}
\hline Gene & NCBI reference & Primer sequences $\left(5^{\prime}-3^{\prime}\right)$ & Product size (bp) \\
\hline$M D R-1$ & NM_000927 & $\begin{array}{l}\text { F: GCTCCGATACATGGTTTTCC } \\
\text { R: TTACAGCAAGCCTGGAACCT }\end{array}$ & 146 \\
\hline$p 21$ & NM_000389 & $\begin{array}{l}\text { F: GGAAGACCATGTGGACCTGT } \\
\text { R: GGCGTTTGGAGTGGTAGAAA }\end{array}$ & 146 \\
\hline$X A F 1$ & NM_017523 & $\begin{array}{l}\text { F: CTCGGTGTGCAGGAACTGTAAA } \\
\text { R: CAGGAACCGCAGGCAGTAA }\end{array}$ & 79 \\
\hline E-cadherin & NM_004360 & $\begin{array}{l}\text { F: TTTTCCCTCGACACCCGATT } \\
\text { R: GTGGTGGTGCCCCACTGTAT }\end{array}$ & 165 \\
\hline$V E G F$ & NM_001171623 & $\begin{array}{l}\text { F: AACTTTCTGCTGTCTTGG } \\
\text { R: TTTGGTCTGCATTCACAT }\end{array}$ & 395 \\
\hline RPL32 & NM_000994 & $\begin{array}{l}\text { F: CATCTCCTTCTCGGCATCA } \\
\text { R: AACCCTGTTGTCAATGCCTC }\end{array}$ & 153 \\
\hline
\end{tabular}

$\mathrm{F}$, forward primer; $\mathrm{R}$, reverse primer.

Table II. Primer sequences for methylation-specific PCR.

\begin{tabular}{lllcr}
\hline Gene & NCBI reference & \multicolumn{1}{c}{ Primer sequences (5'-3') } & $\begin{array}{c}\text { Location to } \\
\text { transcription site }\end{array}$ \\
\hline$p 21$ & NG_009364 & (M) $\begin{array}{l}\text { F: TGTAGTACGCGAGGTTTCG } \\
\text { R: TCAACTAACGCAACTCAACG } \\
\end{array}$ & (U) $\begin{array}{l}\text { F: TTTTTGTAGTATGTGAGGTTTTGG } \\
\text { R: AACACAACTCAACACAACCCTA }\end{array}$ & -196 to +5 \\
& & & -200 to -1 \\
& & & 2002 \\
\hline
\end{tabular}

M, methylated sequence; $U$, unmethylated sequence; $F$, forward primer; $R$, reverse primer.

Western blot analysis. Cells were seeded in 6-well microtiter plates and treated as described above. The treated cells and xenografts were lysed in ice-cold lysis buffer $[50 \mathrm{mM}$ Tris (pH 7.4), $150 \mathrm{mM} \mathrm{NaCl}, 1 \%$ Triton $\mathrm{X}, 10 \mathrm{mM} \beta$-glycerophosphate, $1 \mathrm{mMNa}_{3} \mathrm{VO}_{4}, 1 \mathrm{mMEDTA}, 1 \mathrm{mM}$ phenylmethylsulfonyl fluoride, $1 \%$ protease inhibitor cocktail (Sigma)]. Protein concentrations were determined using the DC protein assay kit (Bio-Rad, Tokyo, Japan). Protein extract ( $20 \mu \mathrm{g})$ was loaded onto a 7.5 or $12 \%$ SDS-polyacrylamide gel and separated by electrophoresis. The separated proteins were then transferred to a polyvinylidene difluoride membrane (ATTO, Tokyo, Japan). After the membrane was blocked with 5\% non-fat milk overnight, it was incubated with a primary antibody for $1 \mathrm{~h}$, followed by a secondary antibody for $1 \mathrm{~h}$. We used the following human reactive antibodies: Anti-P-gp (1/500), antip21 (1/200) and anti- $\beta$-actin (1/10000) from Sigma; anti-Bax (1/1000), anti-XAF1 (1/200), anti-cyclin B1 (1/200) and anti-cdc2 (1/200) from Santa Cruz Biotechnology Inc. (Santa Cruz, CA, USA); anti-Bcl-2 (1/1000) from BD Biosciences (San Jose, CA, USA); and anti-phospho-cdc2 (p-cdc2) (Tyr15) from Cell Signaling Technology (Danvers, MA, USA). Immunoreactive bands were detected with an ECL detection reagent (Millipore, Billerica, MA, USA). We used $\beta$-actin as the internal standard.
Methylation-specific PCR analysis. The chemical modification of cytosine to uracil by bisulfite treatment is useful for the analysis of the methylation status of a gene promoter. In this reaction, unmethylated cytosines are converted to urasil, whereas methylated cytosines remain as cytosines. Cells were plated in 6-well microtiter plates and treated with Aza (or the vehicle) for $72 \mathrm{~h}$. Thereafter, genomic DNA was extracted from the cells by using the QIAamp DNA Blood Mini Kit (Qiagen). The extracted DNA was then subjected to bisulfite treatment using the Methylamp DNA Modification Kit (Epigentek Group Inc., Brooklyn, NY, USA) according to the manufacturer's instructions. The modified DNA was used as a template for methylation-specific PCR. Primer sequences are listed in Table II. The PCR reaction was performed at $94^{\circ} \mathrm{C}$ for $5 \mathrm{~min}$, followed by 38 cycles at $94^{\circ} \mathrm{C}$ for $30 \mathrm{sec}, 55^{\circ} \mathrm{C}$ (methylated sequence) or $60^{\circ} \mathrm{C}$ (unmethylated sequence) for $1 \mathrm{~min}, 72^{\circ} \mathrm{C}$ for $1 \mathrm{~min}$, and then at $72^{\circ} \mathrm{C}$ for $5 \mathrm{~min}$. After amplification, the $\mathrm{PCR}$ products were electrophoresed on a $3 \%$ agarose gel.

Statistical analysis. Statistical analyses were performed using the Dunnett's test or the Tukey-Kramer test for the comparison of multiple groups. A value of $\mathrm{P}<0.05$ was considered to be statistically significant. 
A

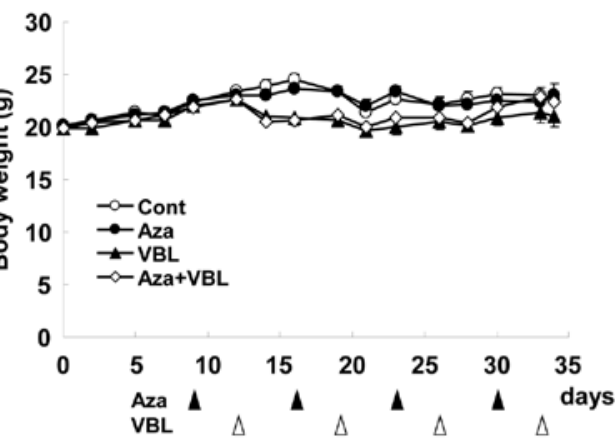

B

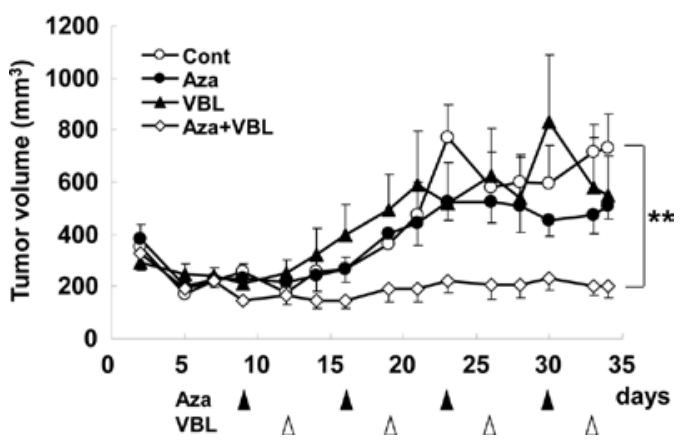

C

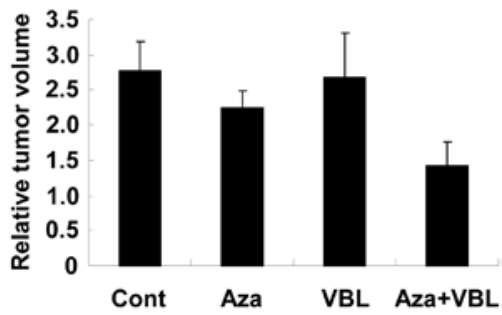

D

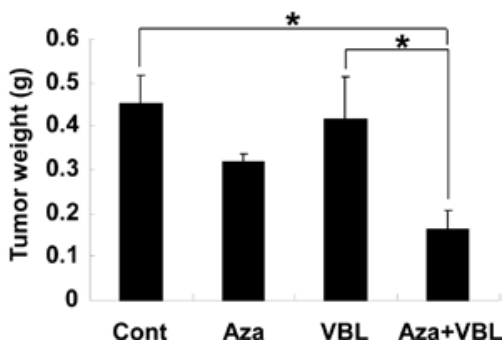

Figure 1. Effect of Aza and VBL on the development of Caki-1 tumors in a xenograft model. Aza $(1.5 \mathrm{mg} / \mathrm{kg}) \mathrm{was}$ administered by i.p. injection on days 9, 16 , 23 and 30 after cell transplantation, and VBL $(1.5 \mathrm{mg} / \mathrm{kg}$ ) was administered by i.p. injection on days 12, 19, 26 and 33. (A) Body weight was measured every 2 or 3 days. Tumor diameter was also measured every 2 or 3 days and (B) tumor volume and (C) relative tumor volume were calculated as described in Materials and methods. (D) Tumor weight was measured after the removal of the tumor on day 34 . Each value represents the mean $\pm \mathrm{SE}(\mathrm{n}=6)$. ${ }^{*} \mathrm{P}<0.05$ and ${ }^{* *} \mathrm{P}<0.01$, significantly different as shown by the Tukey-Kramer test.

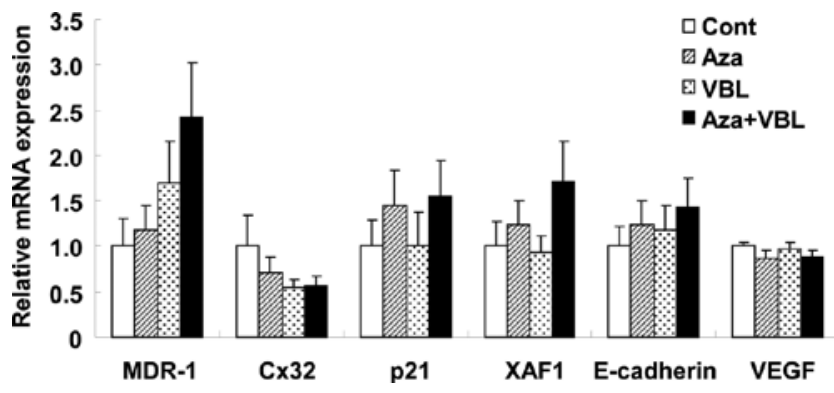

Figure 2. Effect of Aza and VBL on mRNA expression in Caki-1 xenografts. Aza and VBL were administered as described in the legend to Fig. 1. Total RNA was extracted from xenografts and the mRNA levels were determined by real-time PCR. The mRNA level of each gene was normalized to the internal standard RPL32 and presented as a ratio to the control. Each value represents the mean $\pm \operatorname{SE}(n=5-6)$.

\section{Results}

Effect of Aza and VBL on tumor growth in a Caki-1 xenograft model. The body weight of mice decreased by 1-3 g after the first administration of VBL. However, no further loss of body weight resulted from additional VBL injections (Fig. 1A), suggesting that Aza and VBL were well tolerated at the doses used in this study.
Although the treatment with Aza or VBL alone caused little effect on tumor growth, tumor volume was significantly suppressed by co-treatment with Aza and VBL, compared to the control group (Fig. 1B). Relative tumor volume tended to be lower in the co-treatment group (Fig. 1C). In addition, tumor weight was significantly decreased in the co-treatment group, compared to the control and VBL alone groups (Fig. 1D). These results confirm that the combined treatment with Aza and VBL is effective in a Caki-1 xenograft model.

Effect of Aza and VBL on the expression of $m R N A$ and protein in Caki-1 xenografts. We then investigated the mechanisms of this combined effect. As for the expression of mRNA in the xenografts (Fig. 2), the MDR1,p21, and the X-linked inhibitor of apoptosis protein (XIAP) associated factor-1 (XAF1) mRNA expression tended to be increased in the co-treatment group. On the contrary, the mRNA expression of Cx32 was decreased and that of vascular endothelial growth factor (VEGF) and E-cadherin was unaffected in the co-treatment group.

As shown in Fig. 3, we determined the protein expression levels of several additional factors involved in the cell cycle and apoptosis as well as the factors whose mRNA expression was up-regulated by drug treatment. The expression of P-gp was suppressed in the xenografts of the co-treatment group, yet $M D R 1$ mRNA expression was increased. In the co-treatment 
A

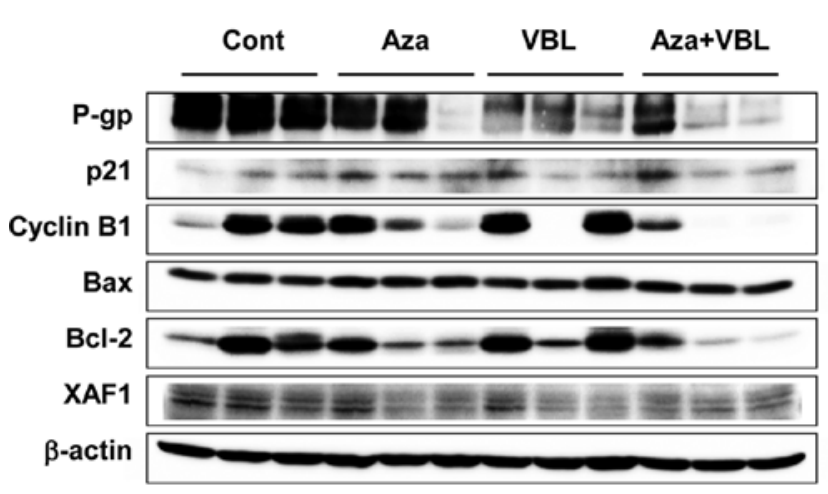

B

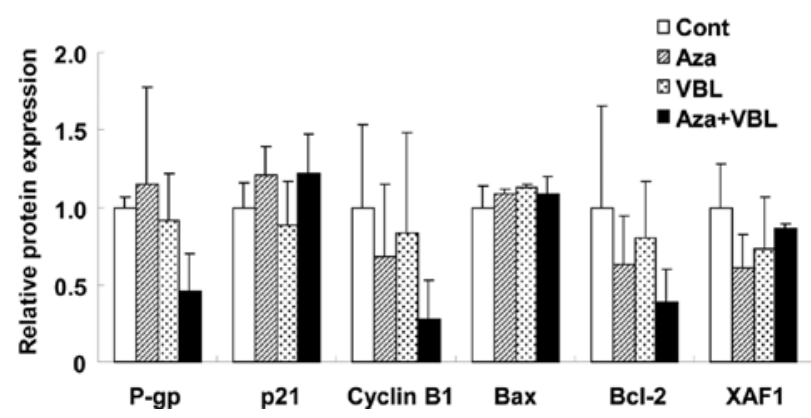

Figure 3. Effect of Aza and VBL on protein expression in Caki-1 xenografts. Aza and VBL were administered as described in the legend to Fig. 1. Whole cell lysates isolated from xenografts were analyzed by Western blotting using the indicated antibodies. (A) The bands corresponding to three samples per group are shown. (B) The intensity of the bands shown in panel A was normalized to the internal standard $\beta$-actin and presented as a ratio to control. Each value represents the mean $\pm S D(n=3)$.

group, p21 expression was slightly increased. Cyclin B1 and Bcl-2 expression was decreased although Bax expression was unaltered. $X A F 1$ mRNA was up-regulated, but its protein expression was not increased.

Effect of Aza and VBL on the cell growth and cell cycle of $R C C$ cell lines in vitro. The in vitro assays were performed with three different RCC cell lines: Caki-1, 786-O and A498. In all three cell lines, cell growth was inhibited in a dosedependent manner by the treatment of Aza alone. Moreover, the cytotoxicity of $10 \mathrm{nM}$ VBL alone was enhanced by pre-treatment with Aza (Fig. 4). From the results of the MTT assay, we selected $0.1 \mu \mathrm{M}$ (Caki-1 and A498) and $0.5 \mu \mathrm{M}$ (786-O) for the concentration of Aza that induced a potent combinatory effect. Cell cycle analysis (Fig. 5) showed that the cell population in the subG1 phase was increased by drug treatment in all cell lines. In particular, in the 786-O and A498 cells, the ratio of subG1 was increased more potently by co-treatment than by treatment with Aza or VBL alone. In the Caki-1 cells, the ratio of subG1 in the co-treated cells was equal to that in the VBL-treated cells.
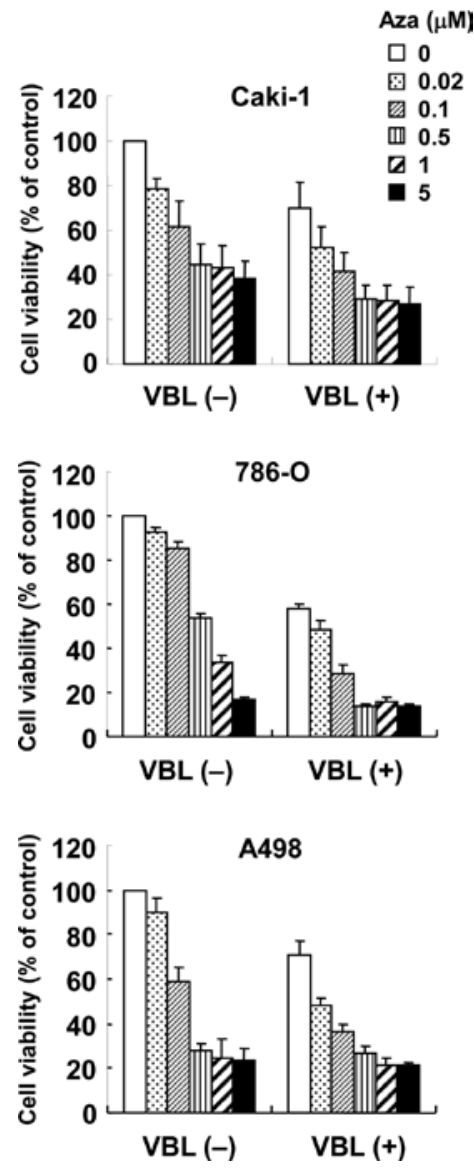

Figure 4. Effect of the combined treatment with Aza and VBL on Caki-1, 786-O and A498 cell proliferation. Cells were treated with the indicated concentrations of Aza for $72 \mathrm{~h}$ followed by $10 \mathrm{nM}$ of VBL for $48 \mathrm{~h}$. Cell viability was determined by MTT assay. Each value represents the mean \pm SD $(n=3)$.

Effect of Aza and VBL on protein expression in RCC cell lines in vitro. In the 786-O and A498 cells, the VBL-induced up-regulation of P-gp was depressed by co-treatment with Aza and VBL (Fig. 6A). In addition, Bcl-2 expression was inhibited in the Aza-treated and co-treated cells. This result is in agreement with the increase of subG1 cells observed in the cell cycle analysis (Fig. 5). However, significant changes in $\mathrm{P}-\mathrm{gp}$, Bax and Bcl-2 expression were not found in the Caki-1 cells (Fig. 6A). As the ratio of subG1 cells was only approximately $50 \%$ by co-treatment in Caki-1 (Fig. 5), we also investigated the expression of cell cycle factors. As shown in Fig. 6B, the expression of p21 was increased by drug treatment. The expression of cyclin B1 and p-cdc2 was almost abolished by treatment with VBL alone but was partially recovered by co-treatment. There was no difference in the expression of cdc2. The changes in protein expression obtained by both in vivo and in vitro assays are summarized in Fig. 7.

Methylation status analysis of the p21 gene promoter in Caki-1 cells. Finally, we focused on the Aza-induced upregulation of p21 expression and investigated the methylation status of the promoter region of the $p 21$ gene to clarify the direct target genes of Aza. The expression of p21 mRNA was 2.7-fold higher in the cells treated with $5 \mu \mathrm{M}$ Aza than in the 


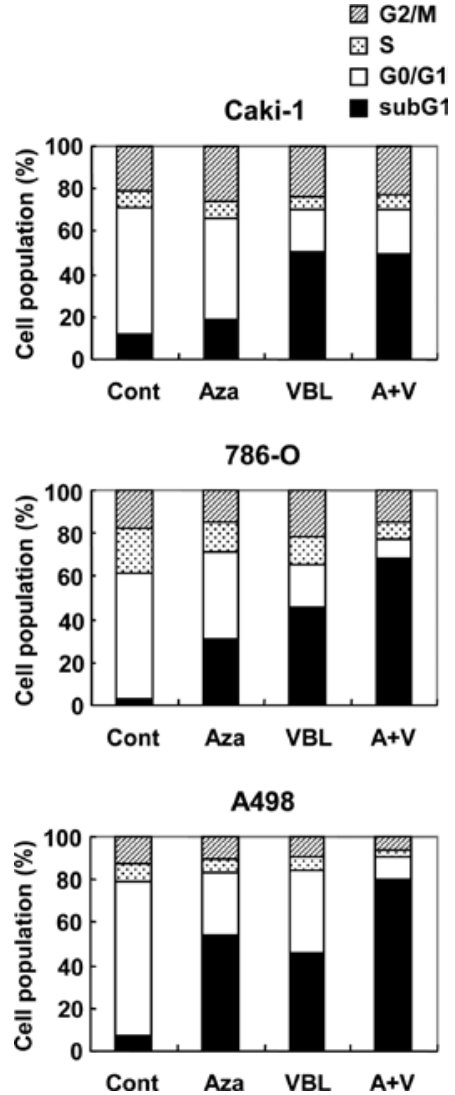

Figure 5. Effect of the combined treatment with Aza and VBL on Caki-1, 786-O and A498 cell cycle distribution. Cells were treated with $0.1 \mu \mathrm{M}$ (Caki-1 and A498) or $0.5 \mu \mathrm{M}$ (786-O) of Aza for $72 \mathrm{~h}$ followed by $10 \mathrm{nM}$ of VBL for $48 \mathrm{~h}$. After treatment, cell cycle analysis was performed by flow cytometry. Each value represents the mean $(n=3)$. A+V, Aza followed by VBL.

control cells (Fig. 8A). However, methylated sequences were not detected in the control cells by methylation-specific PCR (Fig. 8B).

\section{Discussion}

We previously reported that the cytotoxicity of VBL was enhanced by pre-treatment with Aza in Caki-1 cells, using an in vitro assay (27). In this study, we investigated the effects of the combined treatment with Aza and VBL in a Caki-1 xenograft model and in a series of RCC cell lines in vitro.

In the first set of experiments, we found that xenograft tumor volume and weight were significantly reduced by co-treatment with Aza and VBL, compared to the control. Moreover, there was only minimal loss of body weight in the mice treated with the drugs. From these observations, the combination therapy with Aza and VBL seems to be safe and effective against Caki-1 cell proliferation in vivo.

We investigated the mechanisms of this combination effect by measuring the mRNA and protein expression levels in isolated xenografts. The high expression of P-gp is considered to be one of the causes of drug resistance in cancer, and VBL is a substrate of P-gp. In this study, we found that xenograft $\mathrm{P}$-gp expression was lower in the co-treatment group than in the control or VBL treatment alone groups. It is possible that the cellular concentration of VBL was increased and that the
A

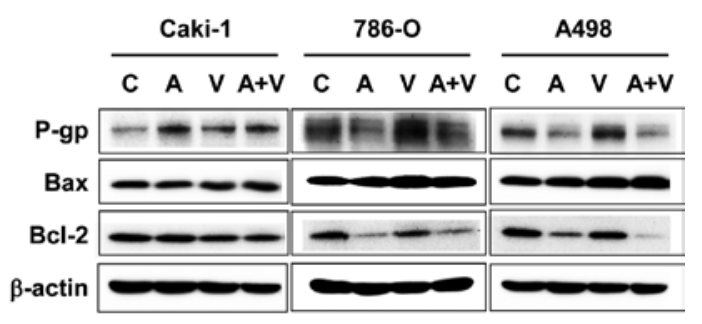

B

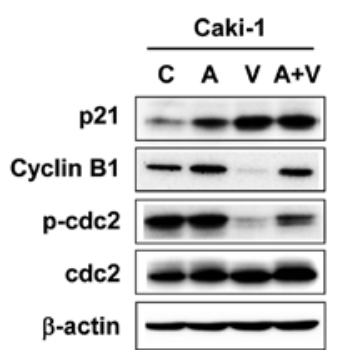

Figure 6. Effect of the combined treatment with Aza and VBL on the protein expression in Caki-1, 786-O and A498 cells. Cells were treated as described in the legend to Fig. 5. Whole cell lysates were analyzed by Western blotting using the indicated antibodies. $\beta$-actin was used as the internal control. (A) Effect of Aza and VBL on the expression of P-gp and apoptotic regulators in the three cell lines. (B) Effect of Aza and VBL on the expression of cell cycleassociated proteins in Caki-1 cells. C, control; A, Aza alone; V, VBL alone; $\mathrm{A}+\mathrm{V}$, Aza followed by VBL. The data shown are representative of three independent experiments.

antitumor effect of VBL was thus potentiated in the co-treatment group. As P-gp can contribute to RCC chemoresistance $(13,14)$, treatment with Aza in combination with cytotoxic drugs is a very promising approach for overcoming RCC drug resistance.

In this study, changes in P-gp expression were not parallel with changes in MDRI mRNA expression because MDRI mRNA levels were up-regulated in the co-treatment group. The following report however, helps to clarify the uncoupling between mRNA and protein expression. Yague et al reported that MDR 1 mRNA was up-regulated by short-term exposure of leukemic cells to colchicine and VBL, whereas P-gp expression was not increased (30). The authors further clarified that this translational blockade resulted from the failure of mRNA to associate with the ribosomes. In our in vivo study, certain regulatory mechanisms could have possibly affected the translation of P-gp.

It has been reported that $\mathrm{p} 21$ is an inhibitor of cyclindependent kinases and an inducer of both G1 and G2 arrest $(31,32)$. Cyclin B1 is crucial for the transition from the $\mathrm{G} 2$ to the $M$ phase. Aza induces $\mathrm{G} 2 / \mathrm{M}$ arrest via the up-regulation of the p21 protein and the down-regulation of cyclin B1 mRNA in pancreatic cancer cells (33). In our study, p21 expression was moderately increased and cyclin B1 was decreased in the co-treatment group with Aza and VBL, compared to the control or VBL treatment alone groups. Therefore, we speculated that G1 and G2 arrest could contribute to this combined effect. In addition, we speculated that apoptosis could be potentiated by the co-treatment because 


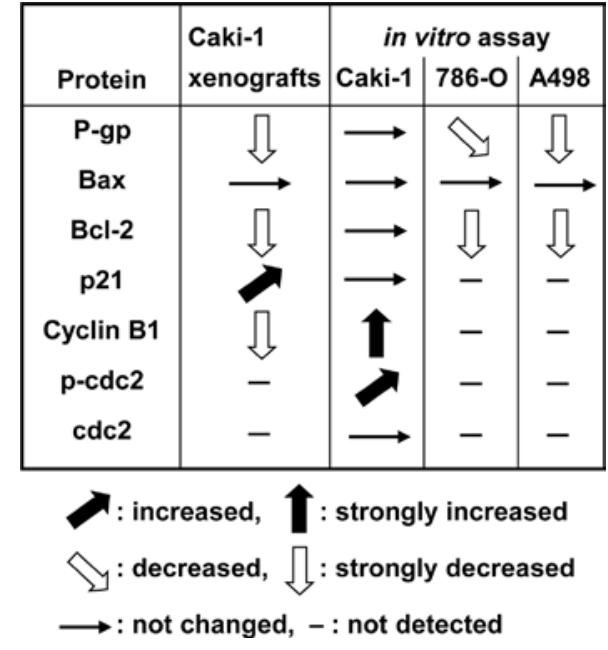

Figure 7. Summary of the changes in protein expression in the Aza/VBL co-treatment group, compared to VBL alone treatment group. Data were obtained from the in vivo and in vitro assays.

the expression of the anti-apoptotic Bcl-2 was suppressed, but that of pro-apoptotic Bax remained unchanged.

We previously reported that Aza $(2.5 \mathrm{mg} / \mathrm{kg}$, by i.p. injection, once a week) alone markedly inhibited the growth of Caki-1 xenografts and that $C x 32$ mRNA expression was restored in the xenografts, which suggested the contribution of $\mathrm{Cx} 32$ to the antitumor effect of Aza (34). In addition, the intratumoral VEGF content was decreased by Aza treatment. In the present study, however, the mRNA expression of Cx32 was not increased and that of VEGF was unaffected both by Aza alone and by co-treatment with Aza and VBL. This is possibly due to the fact that we administered a smaller dose of Aza in this study $(1.5 \mathrm{mg} / \mathrm{kg})$ than in the previous one $(2.5 \mathrm{mg} / \mathrm{kg})$. It is possible that Cx32 and VEGF did not mediate the Azainduced antitumor effect observed in the present study.

E-cadherin is a tumor-suppressor protein that can inhibit cell invasion and negatively regulate cell proliferation (35). XAF1 directly binds to XIAP and antagonizes XIAP-mediated caspase inhibition (36). It has been reported that low XAF1 expression in RCC tissues is associated with poor prognosis (37). In our study, however, we did not find a significant increase of E-cadherin mRNA and XAF1 protein in the co-treatment group. Thus, we speculated that E-cadherin and XAF1 are not involved in the mechanism underlying the combined effect of Aza and VBL.

We then examined whether the combined effect of Aza and VBL was generally observed in other RCC cell lines. Using in vitro assays, we showed that the cytotoxic effect of VBL was enhanced by pre-treatment with Aza in 786-O and A498 cells, similar to what was observed in the Caki-1 cells.

However, the mechanisms underlying this combined effect were, to some extent, different across the three RCC cell lines. In the 786-O and A498 cells, the population in the subG1 phase was increased and Bcl-2 expression was depressed by co-treatment with Aza and VBL, compared to VBL treatment alone. Therefore, we speculated that the mitochondrial-induced apoptosis mainly contributed to the combined effect in these two cell lines. However, cell cycle regulation could be involved in the combined effect observed in the Caki-1 cells. Although
A

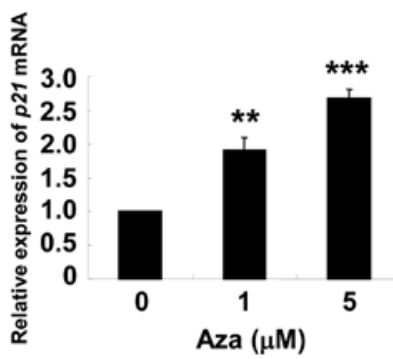

B

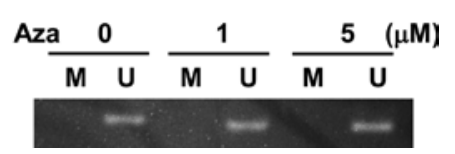

Figure 8. (A) Effect of Aza on the expression of $p 21$ mRNA in Caki-1 cells Cells were treated with 0,1 and $5 \mu \mathrm{M}$ Aza for $72 \mathrm{~h}$. After the treatment, $p 21$ mRNA levels were determined by real-time PCR. The mRNA level was normalized to the internal standard RPL32 and presented as a ratio to the control. Each value represents the mean $\pm \mathrm{SD}(\mathrm{n}=3) .{ }^{* * *} \mathrm{P}<0.01$ and ${ }^{* * * *} \mathrm{P}<0.001$, significantly different from the control as shown by the Dunnett's test. (B) Analysis of the methylation status of the $p 21$ gene promoter in Caki-1 cells. Cells were treated with 0,1 and $5 \mu \mathrm{M}$ Aza for $72 \mathrm{~h}$. After the treatment, methylation-specific PCR analysis was performed using bisulfite-modified DNA. Lane M indicates the presence of methylated DNA; lane U, the presence of unmethylated DNA.

the cyclin B1/p-cdc2 complex, an inactive form of this complex, was almost abolished by treatment with VBL alone, the expression was partially sustained by co-treatment with Aza and VBL. It has been reported that the expression of cyclin B1 and the kinase activity of cdc2 peak at $24 \mathrm{~h}$ and are markedly reduced $48 \mathrm{~h}$ after treatment with anti-microtubule agents, such as paclitaxel (38). Yan et al reported that $\mathrm{G} 2 / \mathrm{M}$ arrest (induced by an alkylating agent) could be prolonged for $48 \mathrm{~h}$ after co-treatment with an inhibitor of DNA methyltransferase. In the above-mentioned studies, the expression of cyclin B1/ $\mathrm{p}$-cdc2 was continuously increased until $48 \mathrm{~h}$ after co-treatment with these two agents, whereas it was reduced $48 \mathrm{~h}$ after treatment with the alkylating agent alone (39). In our study with the Caki-1 cells, the expression of cyclin B1/p-cdc2 was partially maintained for $48 \mathrm{~h}$ after VBL treatment in the co-treated cells. It is possible that $\mathrm{G} 2$ arrest was prolonged by the co-treatment with Aza and VBL, resulting in a more potent decrease in cell viability compared to the VBL treatment alone.

From the results of the present study, it is suggested that apoptosis contributes to a greater extent to the combined effect of Aza and VBL in the 786-O and A498 cells than in the Caki-1 cells. Of these cell lines, Caki-1 expressed the wild-type $V H L$ gene, whereas 786-O and A498 showed mutations in that same gene (2). VHL mediates the degradation of hypoxia-inducible factor- $\alpha$ (HIF- $\alpha$ ), which plays a key role in the regulation of angiogenesis and glucose metabolism under oxygen-deficient conditions (40). Mutations in the VHL gene 
are frequently observed in RCC (41), where HIF- $\alpha$ constitutively accumulates even in normoxic conditions. While many studies indicate that HIF- $\alpha$ contributes positively to tumor growth (42), apoptosis is induced by chronic hypoxia through the induction of the pro-apoptotic BNip3 protein $(43,44)$. As HIF- $\alpha$ is constitutively expressed in 786-O and A498 cells due to the $V H L$ gene mutation (2), it is possible that these cells are more sensitive to apoptosis than Caki-1 cells.

To clarify the direct target genes of Aza, we investigated the methylation status of the promoter region of the $p 21$ gene. However, we found that the $p 21$ promoter was unmethylated in the control cells by methylation-specific PCR. Therefore, the increase in $p 21$ mRNA expression may not be mediated by the demethylation of the gene. In future studies, it would be of interest to search for other Aza target genes.

Although the expression of P-gp and Bcl-2 was inhibited in the Caki-1 xenografts of the co-treatment group, these expressions were not affected in the in vitro assay with the Caki-1 cells. This discrepancy possibly occurred because the concentration of the drugs that reached the tumor tissue in the xenograft model was different from that of the drugs added to the cultured cells.

In this study, we show that the co-treatment with Aza and VBL significantly suppresses RCC growth in a xenograft model with a minimal decrease in body weight. We suggest that this effect is mediated by the suppression of P-gp, which may facilitate VBL accumulation, as well as the enhancement of apoptosis and cell cycle arrest. In addition, we confirmed this combined effect in several RCC cell lines in vitro. These findings show that Aza could be useful against solid tumors and that the activity of conventional cytotoxic agents can be improved by combination therapy. Finally, we suggest that the combined treatment with Aza and VBL could be a promising novel therapy against RCC.

\section{Acknowledgments}

H.I. is a Research Fellow of the Japan Society for the Promotion of Science. This study was supported by a Grant-in-Aid for Research Fellows from the Japan Society for the Promotion of Science, a Grant-in-Aid for Young Scientists (start-up) from the Japan Society for the Promotion of Science, and Special Funds for Education and Research (Development of SPECT probes for Pharmaceutical Innovation) from the Ministry of Education, Culture, Sports, Science and Technology, Japan.

\section{References}

1. Ferlay J, Shin HR, Bray F, Forman D, Mathers C and Parkin DM: Estimates of worldwide burden of cancer in 2008: GLOBOCAN 2008. Int J Cancer 127: 2893-2917, 2010.

2. Shinojima T, Oya M, Takayanagi A, Mizuno R, Shimizu N and Murai M: Renal cancer cells lacking hypoxia inducible factor (HIF)-1 $\alpha$ expression maintain vascular endothelial growth factor expression through HIF-2 $\alpha$. Carcinogenesis 28: 529-536, 2007.

3. Amato RJ: Chemotherapy for renal cell carcinoma. Semin Oncol 27: 177-186, 2000.

4. Motzer RJ and Russo P: Systemic therapy for renal cell carcinoma. J Urol 163: 408-417, 2000.

5. Escudier B, Eisen T, Stadler WM, et al: Sorafenib for treatment of renal cell carcinoma: Final efficacy and safety results of the phase III treatment approaches in renal cancer global evaluation trial. J Clin Oncol 27: 3312-3318, 2009.
6. Motzer RJ, Hutson TE, Tomczak P, et al: Overall survival and updated results for sunitinib compared with interferon alfa in patients with metastatic renal cell carcinoma. J Clin Oncol 27: 3584-3590, 2009.

7. Motzer RJ,Escudier B, Oudard S, et al: Phase 3 trial of everolimus for metastatic renal cell carcinoma: final results and analysis of prognostic factors. Cancer 116: 4256-4265, 2010.

8. Hudes G, Carducci M, Tomczak P, et al: Temsirolimus, interferon alfa, or both for advanced renal-cell carcinoma. N Engl J Med 356: 2271-2281, 2007.

9. Mizutani Y: Recent advances in molecular targeted therapy for metastatic renal cell carcinoma. Int J Urol 16: 444-448, 2009.

10. Akaza H, Tsukamoto T, Murai M, Nakajima K and Naito S: Phase II study to investigate the efficacy, safety, and pharmacokinetics of sorafenib in Japanese patients with advanced renal cell carcinoma. Jpn J Clin Oncol 37: 755-762, 2007.

11. Coley HM: Mechanisms and strategies to overcome chemotherapy resistance in metastatic breast cancer. Cancer Treat Rev 34: 378-390, 2008.

12. Gottesman MM, Fojo T and Bates SE: Multidrug resistance in cancer: role of ATP-dependent transporters. Nat Rev Cancer 2: 48-58, 2002.

13. Walsh N, Larkin A, Kennedy S, et al: Expression of multidrug resistance markers ABCB1 (MDR-1/P-gp) and ABCC1 (MRP-1) in renal cell carcinoma. BMC Urol 9: 6-12, 2009.

14. Soto-Vega E, Arroyo C, Richaud-Patin Y, Garcia-Carrasco M, Vazquez-Lavista LG and Llorente L: P-glycoprotein activity in renal clear cell carcinoma. Urol Oncol 27: 363-366, 2009.

15. Teodoridis JM, Strathdee G, Plumb JA and Brown R: CpG-island methylation and epigenetic control of resistance to chemotherapy. Biochem Soc Trans 32: 916-917, 2004.

16. Nojima D, Nakajima K, Li LC, Franks J, Ribeiro-Filho L, Ishii N and Dahiya R: CpG methylation of promoter region inactivates E-cadherin gene in renal cell carcinoma. Mol Carcinog 32: 19-27, 2001.

17. Kawakami T, Okamoto K, Ogawa O and Okada Y: Multipoint methylation and expression analysis of tumor suppressor genes in human renal cancer cells. Urology 61: 226-230, 2003.

18. Morrissey C, Martinez A,Zatyka M, et al: Epigenetic inactivation of the RASSF1A 3p21.3 tumor suppressor gene in both clear cell and papillary renal cell carcinoma. Cancer Res 61: 7277-7281, 2001.

19. Xiong H, Chen ZF, Liang QC, et al: Inhibition of DNA methyltransferase induces $\mathrm{G} 2$ cell cycle arrest and apoptosis in human colorectal cancer cells via inhibition of JAK2/STAT3/STAT5 signalling. J Cell Mol Med 13: 3668-3679, 2009.

20. Schneider-Stock R, Diab-Assef M, Rohrbeck A, et al: 5-Azacytidine is a potent inhibitor of DNA methyltransferase $3 a$ and induces apoptosis in HCT-116 colon cancer cells via Gadd45and p53-dependent mechanisms. J Pharmacol Exp Ther 312: 525-536, 2005.

21. Kantarjian H, Issa JP, Rosenfeld CS, et al: Decitabine improves patient outcomes in myelodysplastic syndromes: results of a phase III randomized study. Cancer 106: 1794-1803, 2006.

22. Silverman LR, Demakos EP, Peterson BL, et al: Randomized controlled trial of azacitidine in patients with the myelodysplastic syndrome: a study of the cancer and leukemia group B. J Clin Oncol 20: 2429-2440, 2002.

23. Goffin J and Eisenhauer E: DNA methyltransferase inhibitorsstate of the art. Ann Oncol 13: 1699-1716, 2002.

24. Ishiguro $M$, Iida $S$, Uetake $H$, et al: Effect of combined therapy with low-dose 5-aza-2'-deoxycytidine and irinotecan on colon cancer cell line HCT-15. Ann Surg Oncol 14: 1752-1762, 2007.

25. Morita S, Iida S, Kato K, Takagi Y, Uetake H and Sugihara K: The synergistic effect of 5-aza-2'-deoxycytidine and 5-fluorouracil on drug-resistant tumors. Oncology 71: 437-445, 2006.

26. Flis S, Gnyszka A, Misiewicz-Krzeminska I and Splawinski J: Decytabine enhances cytotoxicity induced by oxaliplatin and 5-fluorouracil in the colorectal cancer cell line Colo-205. Cancer Cell Int 9: 10-19, 2009.

27. Takano Y, Iwata H, Yano Y, et al: Up-regulation of connexin 32 gene by 5-aza-2'-deoxycytidine enhances vinblastine-induced cytotoxicity in human renal carcinoma cells via the activation of JNK signalling. Biochem Pharmacol 80: 463-470, 2010.

28. Basso M, Cassano A and Barone C: A survey of therapy for advanced renal cell carcinoma. Urol Oncol 28: 121-133, 2010.

29. Fujimoto E, Sato H, Shirai S, et al: Connexin 32 as a tumor suppressor gene in a metastatic renal cell carcinoma cell line. Oncogene 24: 3684-3690, 2005. 
30. Yague E, Armesilla AL, Harrison G, Elliott J, Sardini A, Higgins CF and Raguz S: P-glycoprotein (MDR1) expression in leukemic cells is regulated at two distinct steps, mRNA stabilization and translational initiation. J Biol Chem 278: 10344-10352, 2003.

31. Medema RH, Klompmaker R, Smits VA and Rijksen G: p21 ${ }^{\text {waf }}$ can block cells at two points in the cell cycle, but does not interfere with processive DNA-replication or stress-activated kinases. Oncogene 16: 431-441, 1998.

32. Ando T, Kawabe T, Ohara H, Ducommun B, Itoh $\mathrm{M}$ and Okamoto T: Involvement of the interaction between p21 and proliferating cell nuclear antigen for the maintenance of $\mathrm{G} 2 / \mathrm{M}$ arrest after DNA damage. J Biol Chem 276: 42971-42977, 2001.

33. Missiaglia E, Donadelli M, Palmieri M, Crnogorac-Jurcevic T, Scarpa A and Lemoine NR: Growth delay of human pancreatic cancer cells by methylase inhibitor 5-aza-2'-deoxycytidine treatment is associated with activation of the interferon signalling pathway. Oncogene 24: 199-211, 2005.

34. Hagiwara H, Sato H, Ohde Y, et al: 5-Aza-2'-deoxycytidine suppresses human renal carcinoma cell growth in a xenograft model via up-regulation of the connexin 32 gene. Br J Pharmacol 153: 1373-1381, 2008.

35. Asnaghi L, Vass WC, Quadri R, et al: E-cadherin negatively regulates neoplastic growth in non-small cell lung cancer: role of Rho GTPases. Oncogene 29: 2760-2771, 2010.

36. Liston P, Fong WG, Kelly NL, et al: Identification of XAF1 as an antagonist of XIAP anti-Caspase activity. Nat Cell Biol 3 : 128-133, 2001.
37. Kempkensteffen C, Fritzsche FR, Johannsen M, et al: Downregulation of the pro-apoptotic XIAP associated factor-1 (XAF1) during progression of clear-cell renal cancer. BMC Cancer 9: 276-282, 2009.

38. Ling YH, Tornos C and Perez-Soler R: Phosphorylation of Bcl-2 is a marker of $\mathrm{M}$ phase events and not a determinant of apoptosis. J Biol Chem 273: 18984-18991, 1998.

39. Yan L, Donze JR and Liu L: Inactivated MGMT by $\mathrm{O}^{6}$-benzylguanine is associated with prolonged $\mathrm{G} 2 / \mathrm{M}$ arrest in cancer cells treated with BCNU. Oncogene 24: 2175-2183, 2005.

40. Semenza GL: Evaluation of HIF-1 inhibitors as anticancer agents. Drug Discov Today 12: 853-859, 2007.

41. Yao M, Yoshida M, Kishida T, et al: VHL tumor suppressor gene alterations associated with good prognosis in sporadic clear-cell renal carcinoma. J Natl Cancer Inst 94: 1569-1575, 2002.

42. Stoeltzing O, McCarty MF, Wey JS, et al: Role of hypoxiainducible factor $1 \alpha$ in gastric cancer cell growth, angiogenesis, and vessel maturation. J Natl Cancer Inst 96: 946-956, 2004.

43. Weinmann M, Jendrossek V, Handrick R, Guner D, Goecke B and Belka C: Molecular ordering of hypoxia-induced apoptosis: critical involvement of the mitochondrial death pathway in a FADD/caspase-8 independent manner. Oncogene 23: 3757-3769, 2004.

44. Bruick RK: Expression of the gene encoding the proapoptotic Nip3 protein is induced by hypoxia. Proc Natl Acad Sci USA 97: 9082-9087, 2000. 